\title{
UK public's views and perceptions about the legalisation of assisted dying and assisted suicide
}

Panagiotis Pentaris \& Lucy Jacobs

\begin{abstract}
Current debates about assisted dying and assisted suicide cover a series of medical, legal, moral, ethical and religious aspects. Yet, public views on the subject remain underexplored and, therefore, not always accounted for in the formation of public policy. This paper reports on empirical data from a cross-sectional study in the UK in 2019, which examines public views about the legalisation of assisted dying and assisted suicide, by means of a self-administered Qualtrics-based survey (self-devised vignettes). A combination of simple random and convenience sampling was used. Participants $(n=297)$ state their preference that both assisted dying and assisted suicide should be legalised in the UK, while doctors should be legally allowed to support such wishes of patients with an incurable and painful illness from which they will die. The paper concludes that public opinion needs to be further accounted for in policymaking and discourses regarding patient autonomy and dignity of care.
\end{abstract}

Keywords: assisted dying; assisted suicide; public; UK; euthanasia; illness 


\section{INTRODUCTION}

Assisted dying and assisted suicide are two controversial topics of public discourse, which promote emotional debates. Controversies associated with this topic are often rooted in the definitional enquiries about what assisted dying, assisted suicide, or their alternative terms like euthanasia and physician-assisted suicide describe. The National Health System (NHS) in the UK defines assisted suicide, for example, as the act of deliberately assisting or encouraging another person to kill themselves. In the Netherlands, euthanasia is described as a deliberate act to terminate one's life on his/her request (Gevers, 1996). Physician-assisted suicide (or doctor-assisted suicide), on the other hand, describes a voluntary act of administering lethal substances to terminate one's life, on his/her choice, with support, direct or indirect, from a physician (Shiel, n.d.). The diversified descriptors of these phenomena have only added to the already complicated public dialogue in this area.

Despite the medical, legal, religious and political arguments about assisted dying and assisted suicide in the media, parliamentary and academic discourses, the public's views are not always explored or accounted for in these debates (Hendry et al., 2013). Battin et al. (2015) argued that public views and perceptions about voluntarily ending one's life are not always represented and research data is scarce. Such views are primarily evident via cases like Diane Pretty and Tony Nicklison. In their review of the varied qualitative and quantitative studies on this topic, and critical synthesis and analysis, Hendry et al. (2013) identified the four main factors that explain why the public may be for or against assisted dying. Specifically, this review showed that the public may be supportive of legalisation of assisted dying both because of the tendencies to avoid poor quality of life and the desire for good quality of life. The same authors 
concluded that concerns about abuse if assisted dying is legalised are associated with the public's opposition, while values, morale and beliefs may be paramount to the decision.

Research (Bosshard et a., 2006) has shown that the argument for autonomy in death is pertinent, and it often drives the support toward legalising assisted dying. Equally, the desire to avoid unbearable pain remains a supporting statement in the debate (McLean, 2009), yet with caveats like the ethical and legal implications of assisted dying in chronic illnesses; neurogenerative disorders or others.

Other studies have focused on physicians' attitudes toward physician-assisted suicide (Curtis and Tonelli, 2017; Dickinson et al., 2005; Gielen et al., 2008; McCormack et al., 2012; Wilson et al., 2019), and they argue that the legalisation of assisted dying would oppose excellence in palliative care and thus is against the latter's principles (Radbruch et al., 2016), or that the combination of euthanasia with palliative care reflects incompatibilities (Bernheim and Raus, 2017).

The current law, in the UK, on assisted dying (i.e. Suicide Act 1961) is criminalising the act of assisting a person's wishes to terminate their life. This raises a tense and ongoing debate between public policy and public opinion. Public policy is denying the public the option to end their life, if their circumstances (e.g. terminal illness and unbearable pain) inform this preference. In other words, public policy takes away the control of an individual's power over their lives and leaves them susceptible to a possibly painful or otherwise discomforting death (Ekland-Olson, 2014). Yet, what is the public opinion about this area of concern, and what informs these views? The focus on public views about assisted dying and assisted suicide can help identify ethical considerations regarding the expectations of the public and the regulations from policy.

This paper draws on empirical data to add to the current knowledge of the UK public's views and perceptions about assisted dying and assisted suicide, as well as whether either or both 
should be legalised, and under what circumstances (i.e. if an illness is leading to unavoidable death or not).

\section{METHODOLOGY}

This is a cross-sectional study (O'Leary, 2017) that explores the public's attitudes about the legalisation of assisted suicide and/or assisted dying in the UK. For the purposes of this study, we conducted a Qualtrics-based self-administered questionnaire, which was designed anew, but informed by the generic descriptors of the concepts of 'assisted dying' and 'assisted suicide' as put forward by the UK national campaign Dying in Dignity (https://www.dignityindying.org.uk) and the NHS. These are explained later in the paper.

\section{Measurement tool}

The self-administered questionnaire used for this study consisted of three parts and 12 items in total. The first part focused on personal characteristics; the second of four vignette-questions (5-Likert style); and the last part of questions specifically addressing the public's views of whether assisted dying and assisted suicide should be legalised in the UK (style of questions: yes, now or maybe) (Appendix 1). All items are close-ended questions. A Cronbach's alpha analysis showed high internal consistency $(\mathrm{a}=.86)$. Face validity (Field, 2009) of the questionnaire confirmed was confirmed, and construct validity (Westen and Rosenthal, 2003) was established by correlating the scale with the Euthanasia Attitude Scale (EAS) (Tang et al., 2010) $(\mathrm{r}=.49)$ and total scoring mean of 13.35 .

For the purposes of this measurement tool, assisted dying and assisted suicide were described based on the nationally acknowledged definitions offered by the Dying in Dignity campaign (https://www.dignityindying.org.uk), which is one of the associations facilitating the debate about assisted dying and assisted suicide in the UK, as well as the NHS in the UK. Specifically, assisted suicide was described to participants as 'giving assistance to die to people with 
progressive conditions and others who are not dying, inclusive of those having a chronic illness - drugs are self-administered'. Assisted dying was described as 'direct assistance to die to people with a terminal illness, but mentally competent. Drugs are administered by others typically the physician'.

\section{Sample and sampling}

According to Pourhoseingholi, Vahedi and Rahimzadeh (2013), the sample size was calculated using the formula $\mathrm{n}=\mathrm{Z} 2 \mathrm{P}(1-\mathrm{P}) / \mathrm{d}_{2}(Z$ for Confidence Interval $95 \%, P$ for the expected prevalence of $15 \%$ and $d$ for precision, which was calculated at $1 / 4$ of the $P$ ).

A combination of simple random and convenience sampling (Bryman, 2016) was used to recruit participants. The link to the self-administered questionnaire was shared widely, via social media, online advertisements, via newsletters and flyers in hospitals, elderly homes, cafés and job centre offices. Those who decided to partake to the online survey, were initially led to a page which offered more participant information about the study and the contact details of the researcher, if they wished to ask further questions. Those who continued to the survey, simultaneously offered their consent to do so.

\section{Data collection and analysis}

The survey gathered 385 responses, 88 of which consisted of various missing values and were thus excluded from the study. Data was collected via randomly generated links to the online survey. The questionnaire was designed to collect data from both computer/mac users and smart tablets and phones. The data was inserted in and analysed (descriptive and inferential statistics) with SPSS version 25.

Descriptive analyses showed frequencies and percentages of the varied views and among the varied groups in the sample. Phi correlation coefficient was used to measure the strength of the 
association between various variables. Similarly, Pearson's correlation was used to explore the varied links between the variables and establish significance in their relationship, but not indicate causality. T-test analysis helped with comparing the means of the results between different groups of the sample (descriptive statistics).

\section{Ethical considerations}

The study received approval by the University Research Ethics Committee (NAME). Participant information was offered, as well as an opportunity to ask questions of the researcher, prior to taking part in the study. The online survey was fully anonymised, and the information has been kept private in secure and password-protected files, at the author's home university. Participation in the study was voluntary and all participants electronically gave their consent to partake, by agreeing to the terms and conditions of the study and positively responding to the notification that progressing to the study indicates full consent.

\section{RESULTS}

The survey returned 385 responses, yet 88 presented missing values; 297 members of the public participated in this study, of which the majority were women $(66.6 \%)$ and female $(67.3 \%)$. $31.8 \%$ of the participants were men and $32 \%$ of male sex. The largest part of the participants were 35 years old and higher (91.4\%), and $68.3 \%$ of the sample were educated at undergraduate or graduate levels. Last, $57.9 \%$ of the sample identified as White, $28.3 \%$ Black/African/Caribbean, while 51.9\% are Christian, 27.9\% state no religion, $4.7 \%$ Muslim and $4 \%$ atheist. Table 1 depicts the full length of the personal characteristics of the research participants. 
Table 1. Participants' personal characteristics

\begin{tabular}{|c|c|c|c|c|}
\hline Variable & Category & Frequency & Percent & $\begin{array}{l}\text { Mean } \\
(\mathrm{SD})\end{array}$ \\
\hline \multirow[t]{5}{*}{ Gender } & Male & 94 & $31.8 \%$ & \multirow{5}{*}{$\begin{array}{l}1.73 \\
(0.62)\end{array}$} \\
\hline & Female & 198 & $66.8 \%$ & \\
\hline & Bigender & 2 & $0.7 \%$ & \\
\hline & Transgender & 2 & $0.7 \%$ & \\
\hline & TOTAL & 297 & $100 \%$ & \\
\hline \multirow[t]{4}{*}{ Sex } & Male & 95 & $32 \%$ & \multirow{4}{*}{$\begin{array}{l}1.73 \\
(0.62)\end{array}$} \\
\hline & Female & 200 & $67.3 \%$ & \\
\hline & Intersex & 2 & $0.7 \%$ & \\
\hline & TOTAL & 297 & $100 \%$ & \\
\hline \multirow[t]{8}{*}{ Age } & $18-24$ & 1 & $0.3 \%$ & \multirow{8}{*}{$\begin{array}{l}4.81 \\
(1.33)\end{array}$} \\
\hline & $25-34$ & 4 & $1.4 \%$ & \\
\hline & $35-44$ & 52 & $17.5 \%$ & \\
\hline & $45-54$ & 79 & $26.6 \%$ & \\
\hline & $55-64$ & 77 & $25.9 \%$ & \\
\hline & $65-74$ & 53 & $17.9 \%$ & \\
\hline & $>75$ & 31 & $10.4 \%$ & \\
\hline & TOTAL & 297 & $100 \%$ & \\
\hline \multirow{9}{*}{$\begin{array}{ll}\text { Level } & \text { of } \\
\text { education } & \end{array}$} & Nursery school to 8 th grade & 2 & $0.7 \%$ & \multirow{9}{*}{$\begin{array}{l}5.98 \\
(1.63)\end{array}$} \\
\hline & High school graduate, diploma or the equivalent & 44 & $14.8 \%$ & \\
\hline & Trade/technical/vocational training & 14 & $4.7 \%$ & \\
\hline & Associate degree & 4 & $1.4 \%$ & \\
\hline & Bachelor's degree & 113 & $38 \%$ & \\
\hline & Master's degree & 89 & $30 \%$ & \\
\hline & Professional degree & 13 & $4.4 \%$ & \\
\hline & Doctorate degree or postdoctorate & 18 & $6 \%$ & \\
\hline & TOTAL & 297 & $100 \%$ & \\
\hline \multirow{7}{*}{ Ethnicity } & White & 172 & $57.9 \%$ & \multirow{7}{*}{$\begin{array}{l}2.56 \\
(1.92)\end{array}$} \\
\hline & Gypsy/traveller & 2 & $0.7 \%$ & \\
\hline & Asian & 17 & $5.7 \%$ & \\
\hline & Mixed/multiple ethnicity & 10 & $3.4 \%$ & \\
\hline & Black/African/Caribbean & 84 & $28.3 \%$ & \\
\hline & Other & 12 & $4 \%$ & \\
\hline & TOTAL & 297 & $100 \%$ & \\
\hline \multirow[t]{10}{*}{ Religion/belief } & No religion & 83 & $27.9 \%$ & \multirow{10}{*}{$\begin{array}{l}2.79 \\
(2.49)\end{array}$} \\
\hline & $\begin{array}{l}\text { Christian (including Church of England, } \\
\text { Catholic, Protestant, and all other forms of } \\
\text { Christianity) }\end{array}$ & 154 & $51.9 \%$ & \\
\hline & Buddhist & 2 & $0.7 \%$ & \\
\hline & Hindu & 5 & $1.7 \%$ & \\
\hline & Jewish & 6 & $2 \%$ & \\
\hline & Muslim & 14 & $4.8 \%$ & \\
\hline & Atheist & 12 & $4 \%$ & \\
\hline & Secular views & 9 & $3 \%$ & \\
\hline & Spiritual & 12 & $4 \%$ & \\
\hline & TOTAL & 297 & $100 \%$ & \\
\hline
\end{tabular}


Participants were offered two sets of questions exploring their views about whether a patient should be allowed the option of assisted dying or assisted suicide. The first set of questions asked the participants whether a patient with an incurable and painful illness, from which they will die, should be allowed by law to terminate their life. In addition, the questions explored whether the law should permit doctors/physicians to give this patient lethal medication to enable them to carry out their wishes. The second set of questions were the same but referred to a patient who will not die from their incurable and painful illness. Figures 1 and 2 show the public's views.

Figure 1. Should a patient with an incurable and painful illness be supported by law to end their life?

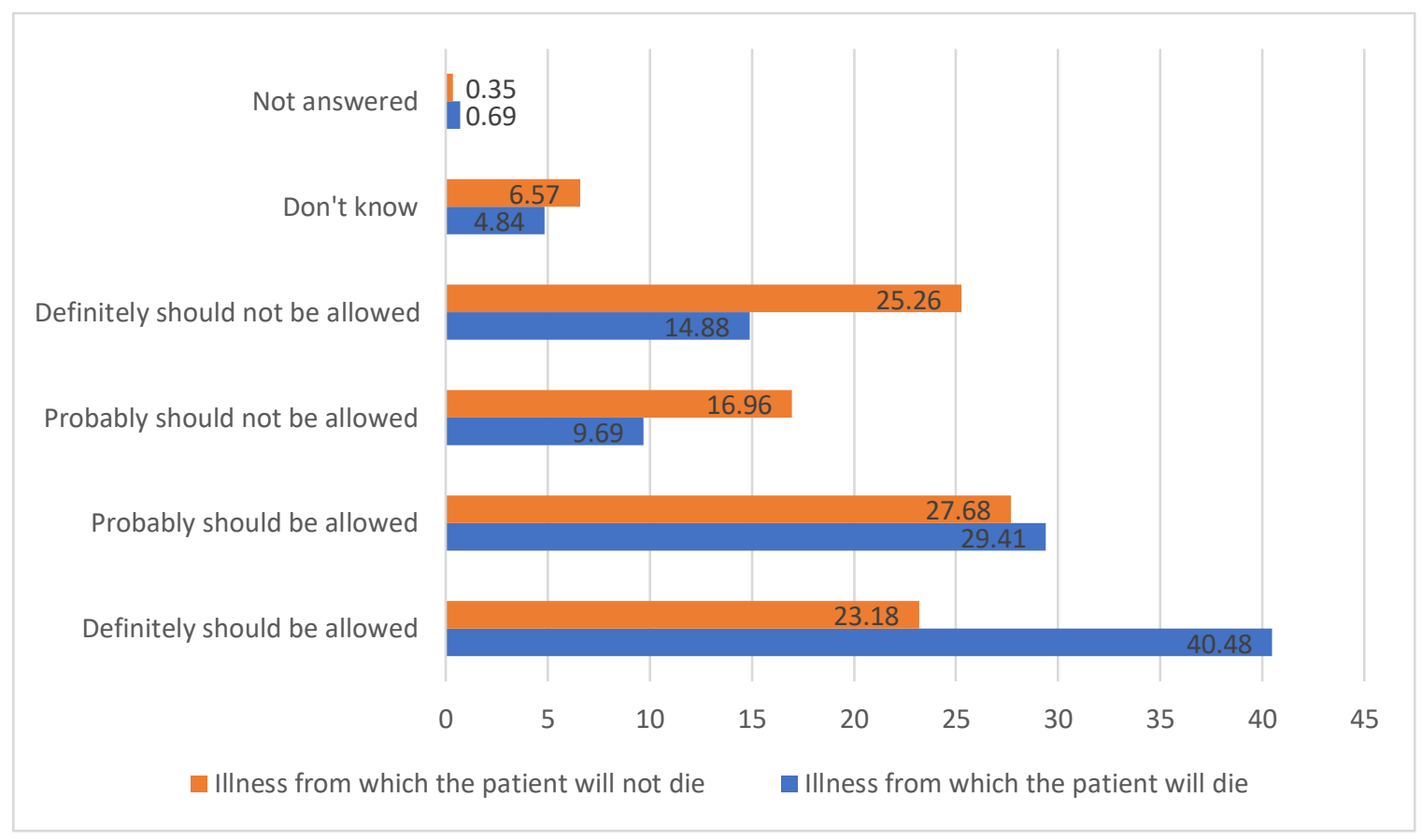


Figure 2. If the person asks for it, should a doctor/physician be allowed by law to give them lethal medication to end their life?

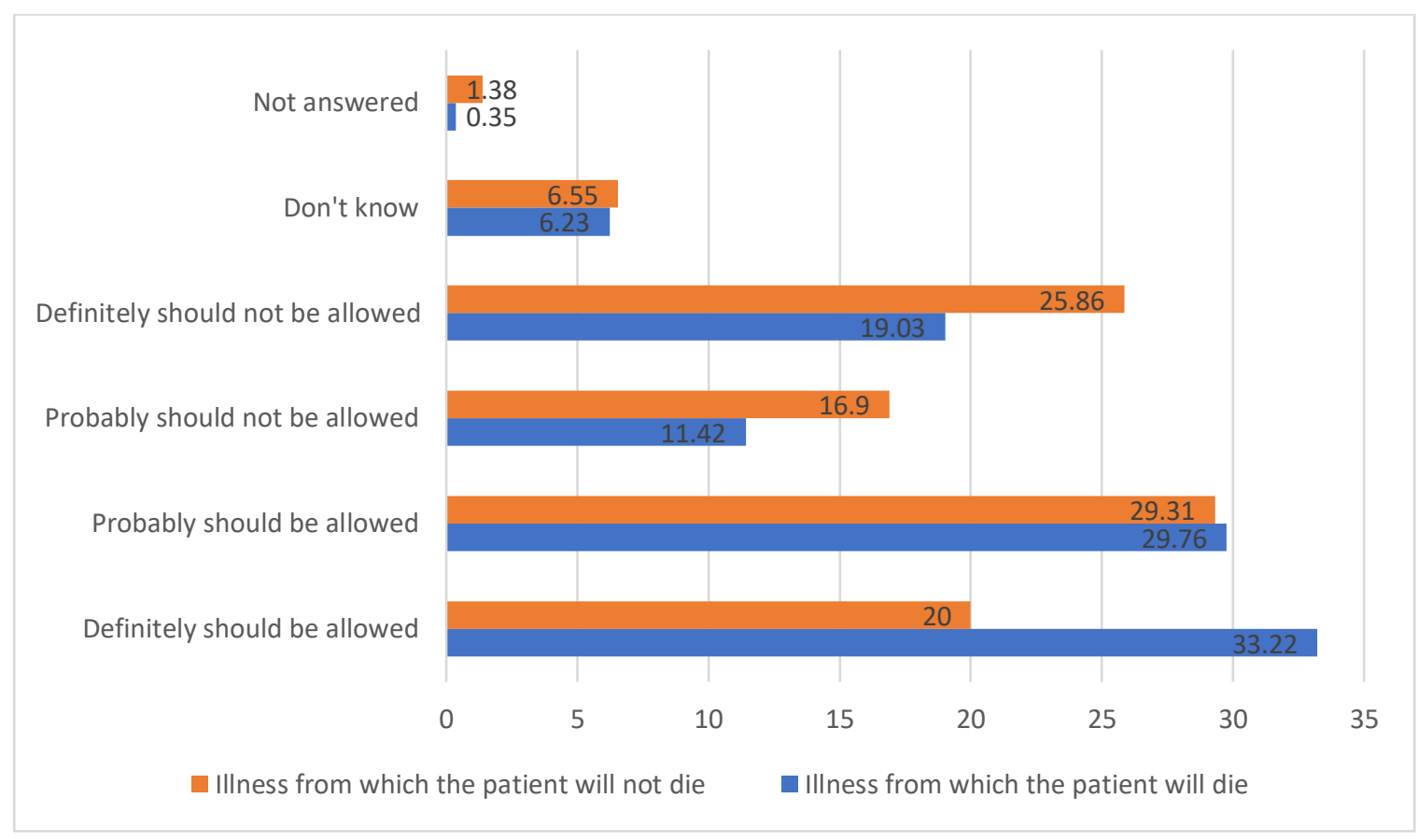

There is a moderate phi coefficient correlation $(\varphi=0.32)$ between these public views and age groups. Sex and views about assisted dying and assisted suicide are strongly and positively correlated $(\varphi=0.8)$; the same applies to the relationship between level of education and views about the patient's choice to end their life $(\varphi=0.7)$, and the doctor's permission to support this choice $(\varphi=0.9)$.

All individuals (100\%) who identified as bigender, transgender or indicated their sex to be intersex, abided by the position that the patient should definitely be allowed to end their life, regardless, if their illness indicates an imminent death, and the doctor/physician should be permitted to support this.

The relationship between ethnicity and views about assisted dying and assisted suicide illuminates cross-ethnic differences. The largest majority of those suggesting that terminating one's life (who is going to die) (directly or indirectly) "should not be permitted" have primarily 
identified as Asian (25\%), Black/African/Caribbean (27.5\%) or Other (36.4\%). These percentages increase when asked about someone who is not going to die (Asian=50.1\%, Mixed ethnic group $=55.5 \%$, Black/African/Caribbean=63.5\%, Other=45.5\%). To the contrary, majority of those identifying as White $(85.3 \%)$ indicated that a patient "should be allowed" this option, and their doctor/physician "should be permitted by law" to support them in that decision. Further, those identifying as Gypsy/Traveller, by $100 \%$, indicate that a doctor/physician "should not be allowed" to help a patient end their life. The majority of participants who identified with mixed ethnic identity (33.3\%) or Black/African/Caribbean (36.3\%) chose the answer that the doctor/physician "should not be allowed" to support the patient.

Similarly, religion-specific differences were revealed from this study. $86.6 \%$ of those declaring no religion support that patients should be offered the opportunity to end their life, and the doctor/physician "should support" them in their decision. Yet, this percentage drops to $69.5 \%$ when the participants are asked about a patient who will not die from their illness. Only participants who identified as Christian $(23 \%)$ or Muslim $(30.8 \%)$ indicated that the patient "should definitely not be allowed" this choice, especially if they are not going to die (Christians=54.1\% \& Muslims=61.5\%). Equally, Christians (26.4\%) Muslims (46.2\%), primarily, suggested that a doctor/physician "should not be allowed" by law to support such decisions of patients. When the same question is asked in relation to a patient who is not going to die from their illness, the percentages shift upwards; Christians $=55.4 \%$, Muslims $=69.3 \%$ and atheists $=41.7 \%$. The percentages of Jewish and Hindus remain the same with little variations between 'definitely should be allowed' and 'probably should be allowed'. Further, $50 \%$ of those identifying as Buddhist, and a small sample of atheists (8.3\%), Christians (12.8\%), with no religion (7.3\%) and Muslims (7.7\%) indicated that this choice "should probably not be allowed". All participants who identified with secular views (100\%) indicate that patients and 
doctors/physicians "should be allowed" these options. Last, only members of the sample who identified as Muslim did not answer the questions (15.4\%).

Table 2 shows the general views of the public, about the legalisation of assisted dying and assisted suicide, based on ethnicity and religious belief/affiliation or lack thereof.

Table 2. Views and perceptions about legalising assisted dying and assisted suicide in the

UK, by ethnic and religious/nonreligious group

\begin{tabular}{|c|c|c|c|c|}
\hline \multirow[t]{2}{*}{ Variable } & \multicolumn{4}{|c|}{ Do you think that assisted suicide should be legalised in the UK? } \\
\hline & Category & Yes & No & Maybe \\
\hline \multirow[t]{9}{*}{ Religion } & No religion & $64.2 \%$ & $9.9 \%$ & $25.9 \%$ \\
\hline & Christian & $37.2 \%$ & $37.9 \%$ & $24.8 \%$ \\
\hline & Buddhist & $0 \%$ & $0 \%$ & $100 \%$ \\
\hline & Hindu & $60 \%$ & $20 \%$ & $20 \%$ \\
\hline & Jewish & $60 \%$ & $0 \%$ & $40 \%$ \\
\hline & Muslim & $15.4 \%$ & $53.8 \%$ & $30.8 \%$ \\
\hline & Atheist & $41.7 \%$ & $25 \%$ & $33.3 \%$ \\
\hline & Secular views & $66.7 \%$ & $11.1 \%$ & $22.2 \%$ \\
\hline & Other & $50 \%$ & $16.7 \%$ & $33.3 \%$ \\
\hline \multirow[t]{8}{*}{ Ethnicity } & White & $60.4 \%$ & $14.2 \%$ & $25.4 \%$ \\
\hline & Gypsy/Traveller & $0 \%$ & $0 \%$ & $100 \%$ \\
\hline & Asian & $43.8 \%$ & $37.5 \%$ & $18.8 \%$ \\
\hline & Mixed ethnicity & $44.4 \%$ & $33.3 \%$ & $22.2 \%$ \\
\hline & Black/African/Caribbean & $21.8 \%$ & $46.2 \%$ & $32.1 \%$ \\
\hline & Other & $10 \%$ & $80 \%$ & $10 \%$ \\
\hline & \multicolumn{4}{|c|}{ Do you think that assisted dying should be legalised in the UK? } \\
\hline & Category & Yes & No & Maybe \\
\hline \multirow[t]{9}{*}{ Religion } & No religion & $68.8 \%$ & $7.5 \%$ & $23.8 \%$ \\
\hline & Christian & $40.7 \%$ & $40 \%$ & $19.3 \%$ \\
\hline & Buddhist & $0 \%$ & $100 \%$ & $0 \%$ \\
\hline & Hindu & $60 \%$ & $20 \%$ & $20 \%$ \\
\hline & Jewish & $60 \%$ & $0 \%$ & $40 \%$ \\
\hline & Muslim & $15.4 \%$ & $46.2 \%$ & $38.5 \%$ \\
\hline & Atheist & $41.7 \%$ & $33.3 \%$ & $25 \%$ \\
\hline & Secular views & $66.7 \%$ & $11.1 \%$ & $22.2 \%$ \\
\hline & Other & $58.3 \%$ & $16.7 \%$ & $25 \%$ \\
\hline \multirow[t]{6}{*}{ Ethnicity } & White & $66.7 \%$ & $12.5 \%$ & $20.8 \%$ \\
\hline & Gypsy/Traveller & $100 \%$ & $0 \%$ & $0 \%$ \\
\hline & Asian & $43.8 \%$ & $43.8 \%$ & $12.5 \%$ \\
\hline & Mixed ethnicity & $22.2 \%$ & $44.4 \%$ & $33.3 \%$ \\
\hline & Black/African/Caribbean & $21.8 \%$ & $52.6 \%$ & $25.6 \%$ \\
\hline & Other & $10 \%$ & $60 \%$ & $30 \%$ \\
\hline
\end{tabular}


A Spearman's correlation showed that positive views about assisted suicide are significantly linked with positive views about assisted dying $(\rho=-1 ; \mathrm{p}<0.01)$.

\section{DISCUSSION}

This study found that public views about assisted suicide and assisted dying depend on whether a patient is facing an imminent and certain death, while other factors like sex, level of education, ethnicity and religion play a part, too. Specifically, this study shows that ethnicity and religion are key determinants of public views about assisted dying and assisted suicide.

In more detail, this study verifies that the public is more inclined to suggest that a patient should be allowed the choice to end their life, either via the route of assisted dying or assisted suicide, if they suffer from an incurable and painful illness, from which they will die. Yet, if the patient is not going to die from their illness, the public's position shifts toward the non-permission of either of these choices, even though the percentage of those suggesting otherwise remains high. This is in line with previous research. Rae et al. (2015) measured New Zealanders' views about physician-assisted dying and whether this should be legalised. The authors found that over $85 \%$ of the participants supported the legalisation of physician-assisted dying and two thirds suggested that in certain medical situations this option is the best for the patient. Similarly, Wilson et al. (2019) found that nurses in New Zealand suggest the legalisation of assisted dying to be a necessity as it will increase patient autonomy, while Oliver (2017) suggest that physicians are more concerned with the responsibility attached to their role, which deprives them from their autonomy (Malpas and Owen, 2016) for the debate about the doctor's role in physician-assisted dying).

The concept of autonomy in patient care has been debated widely both within and outside of the discourses about assisted dying and assisted suicide. In the premises of this paper's interests, patient autonomy has been questioned at times, and the potential for increased patient 
autonomy in the face of the legalisation of assisted dying has as well. Varelius (2016), for example argues that psychiatric assisted dying should be an option for all psychiatric patients, if it were an option, and not merely for those with 'mental clarity' (i.e. mental capacity). If legalising psychiatric assisted dying for such patients is an attempt to increase autonomy, then the opposite is an attempt of decreasing autonomy, which stands against the end of life care principles of autonomy and choice. Other examples that negotiate patient autonomy and the choice for assisted dying include Kouwenhoven et al. (2019), Spence et al. (2017) and Attaran (2015).

Similarly, the public highlights that a doctor/physician "should be allowed" by law to support a patient's decision to end their life, if they will die from their illness, but this view changes when the patient's life is not threatened. This contradicts the position that many physicians hold (McCormack et al., 2012), yet raises ethical dilemmas about what makes excellent palliative care. This debate seems to be deriving from the principle of symptom and pain management in palliative care, as well as informed consent, autonomy and dignity (Watson et al., 2019). This said, is assisted dying the means to excellent palliative care, rather than the objective itself? If so, how is this ambiguity negotiated in the current debates about assisted dying and assisted suicide?

Public opinion is a complex phenomenon to examine, and as such it remains difficult to operationalise. Various studies like Kanagawa et al. (2001) and Bamberg (2011) have explored the self-concept and one's positionality in relation to their dominant or other cultures. For example, ethnicity, religious or non- belief, age, level of education, sex and sexual orientation are key informants of one's worldview. Bourdieu's (1990) work about one's habitus is offering a grounded framework via which this knowledge is supported. Bourdieu argued that disengaging from the realism of the structure of society is key in order to re-engage with primary experience and the subjectification of the objectified realism which is ordering social 
life. With this in mind, current practices and legislation about assisted dying and assisted suicide represent an objective reality merely understood via a positivist lens, while public views are more comfortable in the idea that their formation is the product of personal characteristics and primary experience, rather than structural notions. In these terms, the tensions between public policy and public views seem sensible.

Further, this study highlights a key difference in attitudes toward assisted dying and assisted suicide between people of Asian, Black/African/Caribbean or other than White, mixed and the aforementioned ethnic backgrounds, and those identifying as White. The former is of the view that regardless the imminent death of a patient, assisted dying "should not be allowed". The views intensify when the patient's illness is not threatening their life. Equally, the same group of people suggests that the doctor/physician "should not be allowed" to support the patient's wishes to terminate their life. To the contrary, those identifying as White support the legalisation of assisted suicide and assisted dying more. This is not surprising if one considers that cultural studies have concluded that White people in developed countries tend to strive for more autonomy in social life altogether (Kiecolt and Hughes, 2017), while their counterparts, and especially ethnic minority groups, have shown more evidence of humility and tendencies to accept that not all aspects of their life can be controlled by humans or decisions made by humans (Buchbinder, 2018, for a debate about public health attitudes among ethnic minority groups).

\section{LIMITATIONS OF THE STUDY}

This study is not without its limitations. First and foremost, the findings of this study are not easily transferable to various parts of the population, or the public in the main. The sample size is relatively small to be able to generalize; further research with a sample of increased precision and confidence interval will provide higher and stronger external validity. Yet, this study is a 
good starting point that sketches how members of the public perceive assisted dying and assisted suicide. Further, majority of the participants are educated at various levels; this raises questions about whether the findings are mostly representative of people who have been given the opportunity for education, and perhaps academic engagement with the subject; hence, privy to such debates prior to partaking in this study. In addition to the above, and even though this study identifies attitudes about assisted dying and assisted suicide, by ethnicity and religion, the author recognises that such classification of groups (e.g. Christian, secular, etc.) would be simplistic and naïve, given the complex diversification within each group. Future research can take this into account and explore the association between attitudes towards assisted dying/assisted suicide, religion (or lack thereof) and ethnicity, cross-culturally/cross-nationally. Such study can illuminate more universal knowledge. However, this study sheds some light by generalising some views that have been recorded, which gives rise to future trends in research. Last, it is worth mentioning that both terms, 'assisted dying' and 'assisted suicide', lack a universal definition. This said, the authors acknowledge that this study records the attitudes of the participants, based on the descriptions of the two concepts provided to them (as explained in the methodology section of this paper).

\section{CONCLUSIONS}

This study shows that if a patient is suffering and certainly dying from an incurable illness, then participants are more likely to support the option of assisted dying. Similarly, if the patient is facing an imminent and certain death, participants were supportive of the view that a physician/doctor should support their decision of assisted dying or assisted suicide. Sex, level of education, ethnicity and religion, also play a part in shaping up these views.

Supporting someone to carry out their wishes of assisted dying or assisted suicide remains a criminalised activity in the UK, as in many other countries in the World. Conversations about 
assisted dying occupy the space in public debates more often. A doctor's/physician's or other's active participation in the end of a patient's life steers various debates; primarily legal, ethical and moral. Yet, despite the ongoing disenfranchisement of current practices concerning assisted suicide, referring to the self-administration of drugs that will limit one's life, the latter is indeed an option which patients negotiate in their care plan. The results from this study show that views lean more toward the legalisation of both assisted dying and assisted suicide, however, these views are not fully accounted for and hence public policy may remain distant from those.

Further research in this area will facilitate extensive understanding of the public's awareness of assisted dying and assisted suicide and the ethical, moral, legal, political and religious implications attached to them. Such knowledge can inform a more coherent dialogue between the public and public policy. Additional research to explore shifting patterns of public perceptions toward assisted dying and assisted suicide, as well as causality, will benefit our social understanding of it and policymaking that takes social perceptiveness into account. 


\section{REFERENCES}

Attaran, A. (2015). Unanimity on death with dignity-legalizing physician-assisted dying in Canada. New England Journal of Medicine, 372(22), 2080-2082.

Bamberg, M. (2011). Who am I? Narration and its contribution to self and identity. Theory \& Psychology, 21(1), 3-24.

Battin, M. P. (2015). Rhodes R and Silvers A. Physician assisted suicide: expanding the debate. London, UK: Routledge.

Bernheim, J. L., \& Raus, K. (2017). Euthanasia embedded in palliative care. Responses to essentialistic criticisms of the Belgian model of integral end-of-life care. Journal of Medical Ethics, 43(8), 489-494.

Bosshard, G., Fischer, S., van der Heide, A., Miccinesi, G., \& Faisst, K. (2006). Intentionally hastening death by withholding or withdrawing treatment. Wiener klinische Wochenschrift, 118(11-12), 322-326.

Buchbinder, M. (2018). Access to aid-in-dying in the United States: shifting the debate from rights to justice. American journal of public health, 108(6), 754-759.

Bourdieu, P. (2016). The logic of practice. Stanford, CA: Stanford University Press.

Bryman, A. (2016). Social research methods. Oxford: Oxford university press.

Curtis, J. R., \& Tonelli, M. R. (2017). Palliative Care in the ICU and the role for physicianassisted dying — or lack thereof. Critical care medicine, 45(2), 356-357. 
Dickinson, G. E., Clark, D., Winslow, M., \& Marples, R. (2005). US physicians' attitudes concerning euthanasia and physician-assisted death: a systematic literature review. Mortality, $10(1), 43-52$.

Ekland-Olson, S. (2014). Who lives, who dies, who decides? Abortion, neonatal care, assisted dying, and capital punishment. London, UK: Routledge.

Field, A. (2009). Discovering statistics using SPSS (3rd edition). London, UK: Sage.

Gielen, J., Van Den Branden, S., \& Broeckaert, B. (2008). Attitudes of European physicians toward euthanasia and physician-assisted suicide: a review of the recent literature. Journal of palliative care, 24(3), 173-184.

Gevers, S. (1996). Euthanasia: law and practice in The Netherlands. British medical bulletin, 52(2), 326-333.

Hendry, M., Pasterfield, D., Lewis, R., Carter, B., Hodgson, D., \& Wilkinson, C. (2013). Why do we want the right to die? A systematic review of the international literature on the views of patients, carers and the public on assisted dying. Palliative Medicine, 27(1), 13-26.

Kanagawa, C., Cross, S. E., \& Markus, H. R. (2001). "Who am I?" The cultural psychology of the conceptual self. Personality and Social Psychology Bulletin, 27(1), 90-103.

Kiecolt, K. J., \& Hughes, M. (2017). Racial identity and the quality of life among blacks and whites in the US. Social science research, 67, 59-71.

Kouwenhoven, P. S., van Thiel, G. J., van der Heide, A. Rietjens, J. A., \& van Delden, J. J. (2019). Developments in euthanasia practice in the Netherlands: balancing professional responsibility and the patient's autonomy. European Journal of General Practice, 25(1), 4448.

Malpas, P. J., \& Owens, R. G. (2016). Given that physician-assisted dying is ethical, should it be part of a doctor's role? Mortality, 21(4), 295-304. 
McCormack, R., Clifford, M., \& Conroy, M. (2012). Attitudes of UK doctors towards euthanasia and physician-assisted suicide: a systematic literature review. Palliative Medicine, 26(1), 23-33.

McLean, S. A. (2009). Autonomy, consent and the law. London, UK: Routledge.

O'Leary, Z. (2017). The essential guide to doing your research project. Newbury Park, CA: Sage.

Oliver, P., Wilson, M., \& Malpas, P. (2017). New Zealand doctors' and nurses' views on legalising assisted dying in New Zealand. New Zealand Medical Journal, 130(1456), 10-26. Pourhoseingholi, M.A., Vahedi, M., \& Rahimzadeh, M. (2013). Sample size calculation in medical studies. Gastroenterology and Hepatology form Bed to Bench, 6(1), 17-17.

Radbruch, L, Leget, C., Bahr, P., Müller-Busch, C., Ellershaw, J., De Conno, F., Berghe, P. V., \& board members of the EAPC. (2016). Euthanasia and physician-assisted suicide: a white paper from the European Association for Palliative Care. Palliative medicine, 30(2), 104-116. Rae, N., Johnson, M. H., \& Malpas, P. J. (2015). New Zealanders' attitudes toward physicianassisted dying. Journal of palliative medicine, 18(3), 259-265.

Shiel, W. C. (no date). Medical definition of physician-assisted suicide. Medicine Net: Available at https://www.medicinenet.com/script/main/art.asp?articlekey=32841

Spence, R. A., Blanke, C. D., Keating, T. J., \& Taylor, L. P. (2017). Responding to patient requests for hastened death: physician aid in dying and the clinical oncologist. Journal of oncology practice, 13(10), 693-699.

Tang, W.-K., Mak, K.-K., Kam, P. M.-H., Ho, J. W.-K., Chan, D. C.-Y., Suen, T.-L., Lau, M. C.-K., Cheng, A. K.-C, Wan, Y.-T., Wan, H.-Y., \& Hussain, A. (2010). Reliability and validity of the Euthanasia Attitude Scale (EAS) for Hong Kong medical doctors. American Journal of Hospice and Palliative Care, 27(5), 320-324. 
Varelius, J. (2016). On the moral acceptability of physician-assisted dying for non-autonomous psychiatric patients. Bioethics, 30(4), 227-233.

Watson, M., Ward, S., Vallath, N., Ward, S., Wells, J. (eds.). (2019). Oxford handbook of palliative care. Oxford: Oxford University Press.

Westen, D., \& Rosenthal, R. (2003). Quantifying construct validity: two simple measures. Journal of Personality and Social Psychology, 84(3), 608-618.

Wilson, M., Oliver, P., \& Malpas, P. (2019). Nurses' views on legalising assisted dying in New Zealand: a cross-sectional study. International journal of nursing studies, 89, 116-124.

\section{Appendix A}

\section{Questions measuring views about the legalisation of assisted dying and assisted suicide.}

1. First, a person with an incurable and a painful illness, from which they will die - for example, someone dying of cancer. Do you think that, if they ask for it, a doctor should ever be allowed by law to end their life?

2. Do you think that, if this person asks for it, a doctor should ever be allowed by law to give them lethal medication that will allow the person to take their own life?

3. Now, how about a person with an incurable and painful illness, from which they will not die. Do you think that, if they ask for it, a doctor should ever be allowed by law to end their life?

4. Do you think that, if this person asks for it, a doctor should ever be allowed by law to give them lethal medication that will allow the person to take their own life?

5. Do you think that assisted suicide should be legalised in the UK?

6. Do you think that assisted dying should be legalised in the UK? 
